\title{
Health Risks of Simulium (Boophthora) erythrocephalum (De Geer, 1776) in the Valencian Autonomous Region, Eastern Spain
}

\author{
David López-Peña*, Álvaro Lis-Cantín and Ricardo Jiménez-Peydró \\ Laboratorio de Entomología y Control de Plagas, Institut Cavanilles de Biodiversitat i Biologia Evolutiva (ICBiBE), Parc Científic, \\ Universitat de València (Estudi General), Spain
}

*Corresponding author: David López-Peña, Laboratorio de Entomología y Control de Plagas, Institut Cavanilles de Biodiversitat i Biologia Evolutiva (ICBiBE), Parc Científic, Universitat de València (Estudi General), C/ Catedrático José Beltrán Martínez, 2, 46980

Paterna-València (Spain)

\section{ARTICLE INFO}

Received: 絊 November 01, 2021

Published:

Citation: David López-Peña, Álvaro LisCantín and Ricardo Jiménez-Peydró. Health Risks of Simulium (Boophthora) erythrocephalum (De Geer, 1776) in the Valencian Autonomous Region, Eastern Spain. Biomed J Sci \& Tech Res 39(5)2021. BJSTR. MS.ID.006376.

Abbreviations: S: Simulium; PDH: Public Health Department; GIS: Geographic Information System; M: Meter; ${ }^{\circ} C$ : Celcius Degrees; Minutes; Seconds; MASL: Meters Above Sea Level

\begin{abstract}
The presence and distribution of Simulium erythrocephalum (De Geer, 1776) in the Valencian Autonomous Region is analyzed, an arthropod of medical-sanitary importance due to the marked anthropophilic characteristics exhibited and the tendency to carry out massive attacks. The increasing incidence registered in certain areas as a consequence of their hematophagy, and the meager availability of epidemiological, fauna, bioecological, and distribution data, have led to this study. A field study of 137 samplings was carried out from 2013 to the present in the 14 hydrographic basins of the Valencian Autonomous Region. The study variables were the presence or absence of preimaginal states, environmental and physical-chemical parameters of the water, bite data from the Generalitat Valenciana, population density and incidence of bites by municipality, and geographic location of the population areas. A scarce and reduced presence of the aforementioned species is revealed in the study area. Risk maps of human populations near the detected breeding areas are provided, and the epidemiological interest is discussed due to its vector capacity to transmit pathogens that cause disease. The number of bites registered between 2015, 2016, 2017, and 2018 in the seven health departments involved is provided. The general trend toward an increase in the number of cases is observed year after year, where the highest peaks in the number of cases coincide with the months of June, July, and August, and eventually, September and October. Surveillance and control programs to minimize the problem in the Spanish health system are needed.
\end{abstract}

Keywords: Simuliidae; Anthropophilic; Public Health; Allergic Reactions; Health Departments; Valencian Autonomous Region

\section{Introduction}

Black flies (Diptera: Simuliidae) constitute a harmful group of arthropods due to their bites, allergic reactions, and parasitic diseases. In some places, such as Spain, they do not act as disease transmitters, though it is important not to forget their vector role in the transmission of the parasitic agent triggering human onchocerciasis. Climate change and global warming can contribute to the displacement of Simuliidae from their endemic places
(Central Africa, South America, Central America, and Yemen) to the European continent. Simulium erythrocephalum (De Geer, 1776) is significant because of its possible action as a vector vehicle and transmitter of disease-causing agents, and because it is a telmophagus insect that lacerates the skin and blood capillaries. In addition, it inoculates saliva whose anesthetic, vasodilator, anticoagulant, and antithrombin substances prevent the host 
from perceiving the pain of the bite, prevent blood clotting and contribute to increased blood flow in the area, facilitating its intake [1-3]. These components can cause allergic reactions such as dermatitis (which can persist for several days), poisoning such as simuliotoxicosis $[4,5]$, and even asphyxia due to airway obstruction [6]. This species can cause "Black Fly Fever", a medically recognized syndrome consisting of headache, feverish sweating, chills, swollen lymph glands, joint pain, nausea, lack of energy, laziness, feeling tired and psychological depression [7]. These symptoms are due to the reaction to compounds secreted by the salivary glands [8]. This syndrome can have a significant economic impact due to sick leave, disability compensation, prolonged treatment, hospitalization, and even job loss [7]. The bites of this species can cause intoxication of the blood flow, the symptoms of which consist of accelerated circulation, dyspnea, hyperthermia, hypothermia, nervous disorders and, in extreme cases, death [9].

However, they not only affect man directly but also indirectly, negatively impacting tourist and recreational activities located in rivers and nearby areas, creating economic losses in the tourism sector [1,5]. Therefore, suffering the bites of these Diptera is a brake on the well-being of people and their sources of economic livelihood. Historically, the study of these nematocerous dipterans in Spain was not approached from a health perspective, due to the low significance of their bites in the past. However, from 1995 to the present, the situation has changed considerably. This dipteran is acquiring great relevance in certain regions of the national territory, among which the Valencian Autonomous Region stands out $[10,11]$ where they are colonizing river basins and water channels due to the improvement of the water quality of the rivers, the expansion of the distribution area of plant species used by larvae and pupae as adhesion support, and by the effects on local climatology due to climate change and global warming. All these causes are favoring the increase in simuliid populations, their dispersal, settlement, and colonization in areas where their presence was not perceived in the past. These factors are leading to an exponential increase in the nuisance to human populations close to the breeding, growth, and development areas of the flies. Females of S. erythrocephalum cause discomfort to humans both in Spain [3,12-15] and European countries [16-18]. The simultaneous hatching of adults raises the population level to the status of a plague, causing outbreaks such as those that occurred in the Danube [7] and Ebro [19,20] rivers. Indeed, evidence shows that on certain occasions, administrations have had to resort to the mechanical removal of hydrophytes and helophytes from riverbeds manually or with the aid of an amphibious vehicle to reduce the populations of $S$. erythrocephalum and other hematophagous species. Land and air treatments with formulations based on the use of Bacillus thuringiensis variety israeliensis have been used in areas that required it, such as La Ribera (Figure 1). Of this species, its anthropophilic preference is recognized [18,21], as well as the tendency of females to form swarms and attack in masse [18]. For these reasons, S. erythrocephalum can act as a potential transmitter of Onchocerca volvulus in Europe. In fact, laboratory studies have already shown that it is a competent vector for the transmission of this filaria [22].

The main objective of this work focused on knowing the distribution of S. erythrocephalum, and on graphically representing the range of air displacement of adults and the municipalities subject to their range of displacement, to highlight the localities whose citizens are at low risk of being bitten. In this regard, it should be noted that the Valencian health system is organized in 24 public health departments (PHD) according to DECREE 205/2018, of November 16, of the Consell, which approved the health map of the Valencian Autonomous Region. These departments are equivalent to the health areas contained in the General Health Law (14/1986 of April 25). The health departments are the fundamental structures of the Valencian health system, being the geographical demarcations into which the territory of the Valencian Autonomous Region is divided for health purposes.

\section{Materials and Methods}

From 2013 to the present, a field study has been carried out in which samples were taken from the 14 hydrographic basins and their main tributaries that flow through the Valencian Autonomous Region: Cenia, Cérvol, and Mijares in the province of Castellón; Palancia, Turia, Júcar, and Serpis in the province of Valencia; and Girona, Jalón, Algar, Amadorio, Monnegre, Vinalopó, and Segura in the province of Alicante. For this, a direct sampling was used in each of the points studied, which consisted of an active search for 15 min to detect the presence of the black fly in any substrate of the river. The environmental and physicochemical parameters of the water were also georeferenced and measured. Subsequently, the collected preimaginal individuals were transported under refrigerated conditions to the laboratory where they were processed. Subsequently, taxonomics were identified and classified using dichotomous keys [23,24] and a Leica brand MZ APO stereoscopic microscope assisted with a Leica brand model CLS $100 \mathrm{X}$ cold light source as described in [14,25]. Ultimately, the classified specimens were deposited in the Entomology Collection of the University of Valencia (General Study). Finally, a geographic information system (GIS) was used to prepare the risk map. In addition, note that the bite data provided by the Conselleria de Sanitat Universal i Salut Pública of the Generalitat Valenciana were analyzed using ArcMapTM, ESRI's ArcGIS ${ }^{\circledR}$ software. Through this program, the cartography referring to the DPH of the Valencian Autonomous Region was elaborated, as well as the relation of the population density and incidence of stings by municipality 
based on the flight range of the adults represented by buffers. To obtain these results, cartography in vector format provided by the National Center for Geographic Information was used regarding the geographic location of the population areas and the delimitation of the municipal boundaries. The information regarding population density was obtained from the municipal data bank of the ARGOS information portal of the Generalitat Valenciana. The integration of all these factors, providing them with a range of color, allows us to observe the differences in incidences in the studied area.

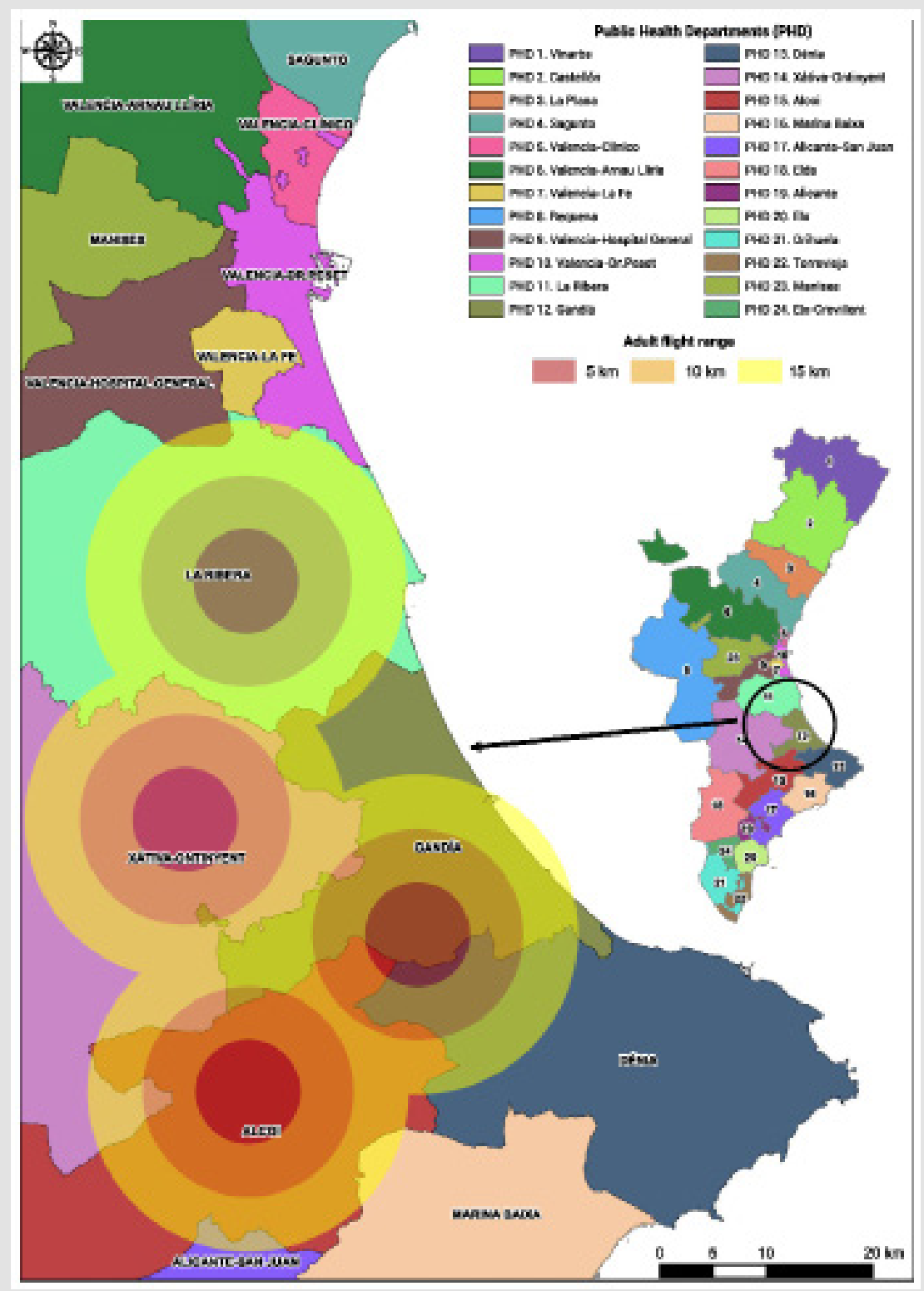

Figure 1: Departments of Health affected, breeding sites, and flight ranges of S. erythrocephalum.

\section{Results}

Of the 137 samplings carried out in the study area, the presence of $S$. erythrocephalum was verified in four sampling stations. Two were located in the middle (SER1) and upper (SER2) section of the Serpis river, and the other two were in the lower section of the Júcar river basin, one in its tributary the Albaida river (JUR1) and another in the insertion from another of its tributaries, the Magro River (JUR2) (Figure 2). From these breeding areas, and knowing that the flight range of the adults of this species is between 20 and $30 \mathrm{~km}[7,8,17]$, three zones of influence were configured around each of the points where the identified species were found.In the maps, a maximum distance of $15 \mathrm{~km}$ was considered as the furthest dispersion range. This decision was made considering that some 
authors confirmed females of the species traveling up to $5 \mathrm{~km}$ in search of hosts from which to obtain blood [19]. At greater distances, it is assumed that the females tend to reduce their movements and therefore their bites, although they are capable of traveling greater distances if required (Figure 2). In this manner, three risk zones were delimited around each of the points where the presence of the species was corroborated. The first zone, with a radius of $5 \mathrm{~km}$, is represented in maroon and indicative of high risk; the second, with a $10-\mathrm{km}$ radius, is represented in orange and indicative of medium risk. The third zone, with a $15-\mathrm{km}$ radius, is represented in yellow and indicative of low risk.

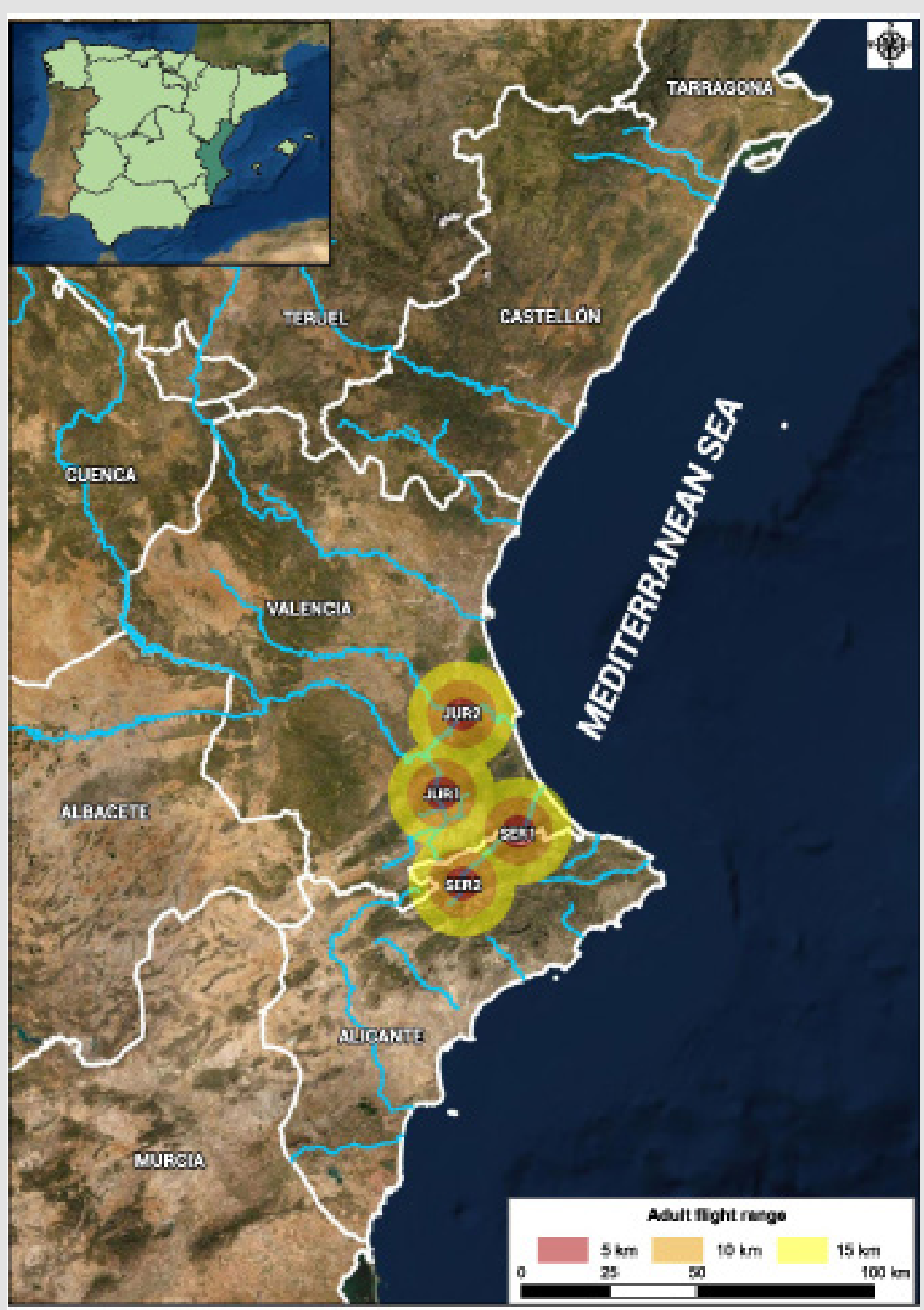

Figure 2: Risk map according to the flight range of S. erythrocephalum females, and information regarding the positive sampling points. SER1 (Villalonga, province of Valencia, 96 meter $(\mathrm{m})$ altitude, $37.6 \%$ relative humidity, $17.9^{\circ} \mathrm{C}$, coordinates $\mathrm{N} 38^{\circ} 52^{\prime}$ $\left.54.7^{\prime \prime} \mathrm{W} 00^{\circ} 14^{\prime} 12.6^{\prime \prime}\right)$, SER2 (Cocentaina, province of Alicante, $372 \mathrm{~m}$ altitude, $21 \%$ relative humidity, $15.3^{\circ} \mathrm{C}$, coordinates $\mathrm{N} 38^{\circ}$ 45' 10.2" W $00^{\circ} 25^{\prime} 29.8^{\prime \prime}$ ), JUR1 (Genovés, province of Valencia, $88 \mathrm{~m}$ altitude, $79.3 \%$ relative humidity, $14.3^{\circ} \mathrm{C}$, coordinates $\mathrm{N} 38^{\circ}$ $59^{\prime} 6.2^{\prime \prime} \mathrm{W} 00^{\circ} 29^{\prime} 6.0^{\prime \prime}$ ) and JUR2 (Algemesí, province of Valencia, $-7 \mathrm{~m}$ altitude, $64.4 \%$ relative humidity, $31.2^{\circ} \mathrm{C}$, coordinates N $39^{\circ} 11^{\prime} 12.7^{\prime \prime}$ W $00^{\circ} 24^{\prime} 39.4$ 
The variable population density of the municipalities located in any of the three risk areas varies between 2 and 4,039 inhabitants/ $\mathrm{km}^{2}$, which means that the risk reaches different magnitudes between localities that are under the influence of the same risk area. The measure of the population density of the municipalities involved is provided in quintiles according to the number of inhabitants per $\mathrm{km}^{2}$ (Figure 3a). This population density can affect the behavior of the females of the species, inciting them to move to a greater or lesser distance in search of their mandatory nutritional requirement. In this way, females of the four populations detected may exhibit different displacement behaviors. As mentioned, the location of the urban nuclei of the municipalities can mark the pattern of flight distance exhibited by the females of $S$. erythrocephalum. Therefore, it can be seen that municipalities with a lower population density (0-25 and 25-79) are at low risk (yellow halo, 10 to $15 \mathrm{~km}$ ), while municipalities with a medium population density (79-206 and 206-894) are in greater numbers and intermediate risk (orange halo from 5 to $10 \mathrm{~km}$ ). Finally, most of the municipalities with the highest population density (894-12,592) fall within the low-risk halo (15 km away from the breeding place), although they also represent the largest number of municipalities located at high risk (red halo 0 to $5 \mathrm{~km}$ ) (Figure $3 \mathrm{~b}$ ). Therefore, although a priori it would be expected that the closer the municipality is to the breeding place the greater the number of recorded bites, the data show that these occur more frequently in population centers with the highest density of inhabitants per $\mathrm{km}^{2}$. This conclusion is met repeatedly throughout the twelve months of the four years studied $(2015,2016,2017$, and 2018) without major alterations. In addition, the General Directorate of Public Health and the Valencian Autonomous Region Health Department were contacted to collect data regarding the number of citizens treated in health centers and hospitals as a result of bites caused by insects. The results of interest provided were relevant. Similarly, significant conclusions are provided when analyzing data provided on the number of consultations attended for insect bites during the years 2015, 2016, 2017, and 2018 of the seven health departments involved (PHD9 Valencia-Hospital General, PHD11 La Ribera, PHD12 Gandía, PHD13 Dénia, PHD14 Xàtiva-Ontinyent, PHD15 Alcoi, PHD17 Alicante-San Juan), whose domains coincide with the flight areas specified in the four breeding foci (Figure 1).

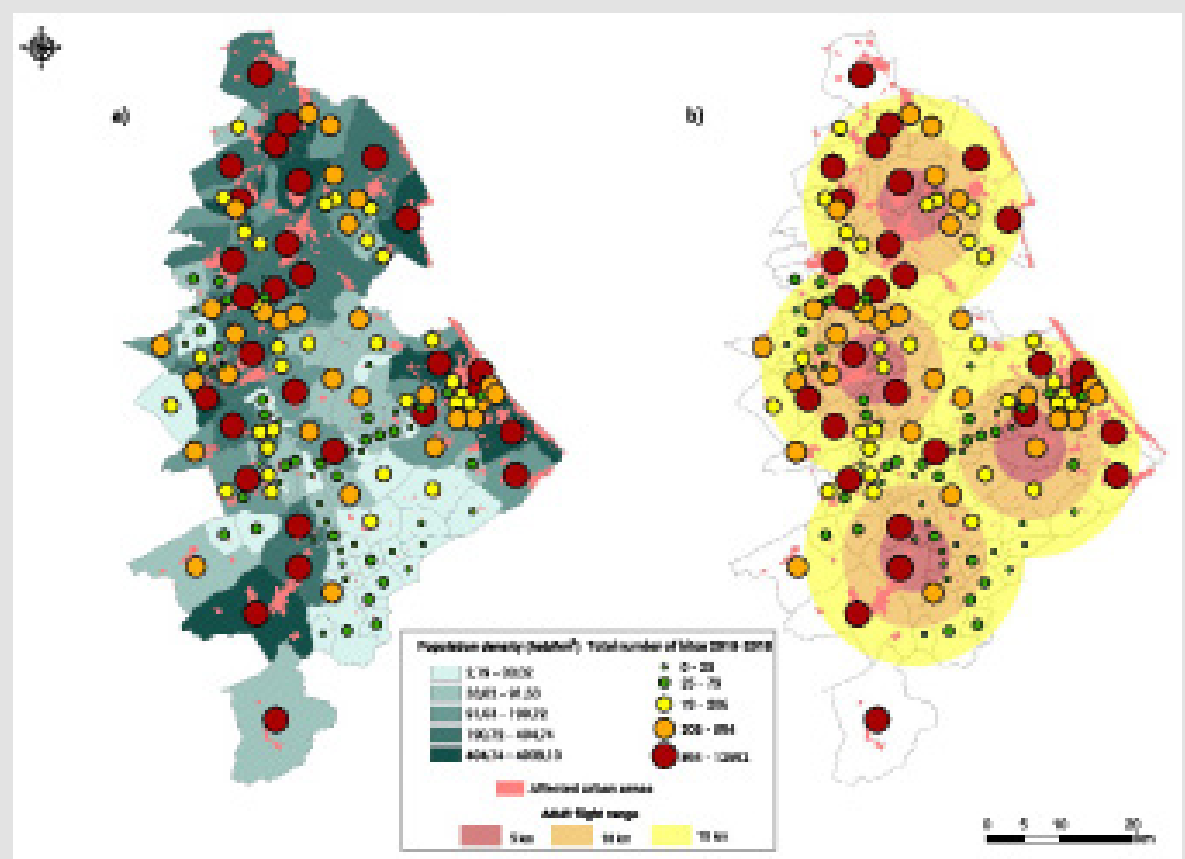

Figure 3: a) Total number of bites by municipality considering population density. b) Situation of the municipalities with respect to the flight ranges of $S$. erythrocephalum and incidence of bites by municipality.

In the first place, and as a consequence of the proximity between the health departments and the breeding centers of $S$. erythrocephalum, it is assumed that the consultations of citizens affected by insect bites were due to the eating habits of this family of Diptera. Second, and considering the data provided from the records of the 12 months of the last 4 years by the aforementioned health departments, it is corroborated that the number of cases treated for bites has increased in general from 2015 to 2018 (Figure 4). Although most health departments experienced a notable increase in the numbers of patients requiring medical care, in others, there has been a decrease. For example, PHD10 declined from 117 medical assistances in July 2015 to 95 in July 2017. PHD13 reduced from 188 in August 2015 to 111 in July 2018; and PHD12, with 2,233 consultations in August 2015, lowered to 1,360 in the same month of 2018. Likewise, and jointly analyzing the computation of PHD care, a general trend of an increasing the number of cases is observed year after year (Figure $5 a$ \& 5b). 


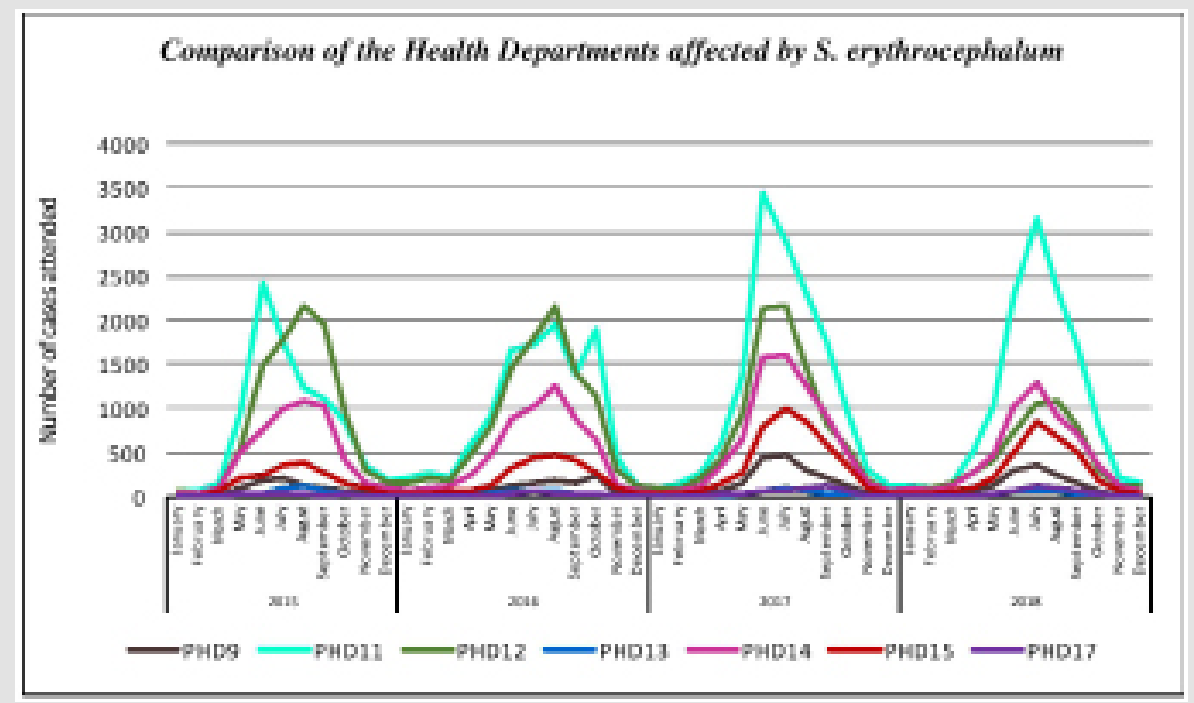

Figure 4: Number of cases of bites treated in health departments of the Valencian Autonomous Region close to breeding sites of S. erythrocephalum.

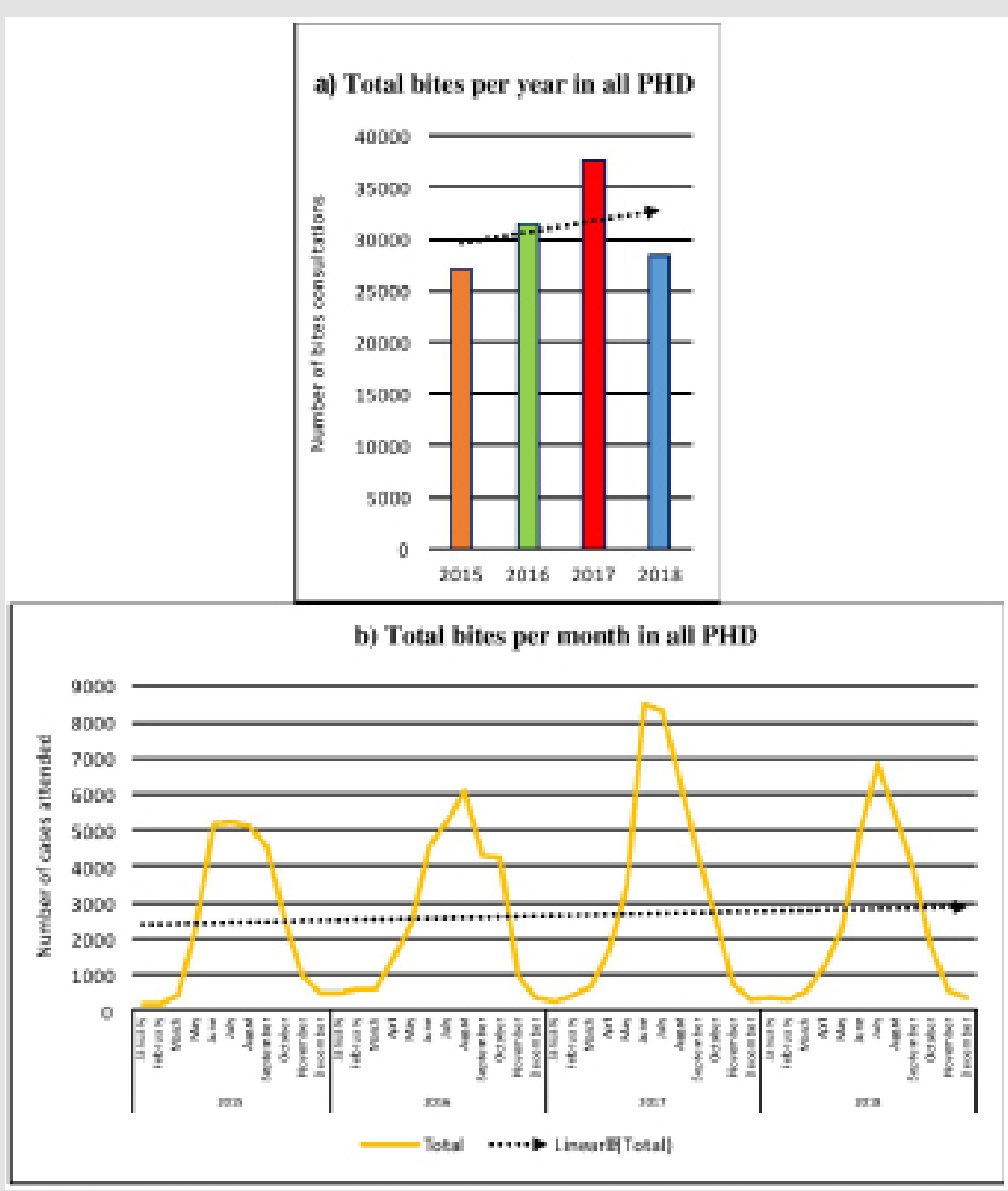

Figure 5: Total number of bite cases treated during the years 2015, 2016, 2017, and 2018 in health departments of the Valencian Autonomous Region close to S. erythrocephalum breeding sites. a) stings per year; and b) stings per month. 
Lastly, it is found that the months in which the highest number of cases have been registered coincide with the annual seasons with favorable physicochemical characteristics for the reproduction, development, and growth of this species. The highest peaks are in the months of June, July, and August and, eventually, in September and October (Table 1). However, analyzing the sum of the data for each year, the months in which the most cases were registered were August 2015 and 2016, and July in 2017 and 2018. Although it is still necessary to deepen the study of the bioecology of this species of sanitary importance, the results of this work reveal the need to consider the ethology of this dipteran when implementing surveillance and control plans to reduce its effects on citizen health.

Table 1: Months in which the highest number of health care for bites has been registered.

\begin{tabular}{|c|c|c|c|c|}
\hline & \multicolumn{3}{|c|}{ MONTH OF HIGHEST INCIDENCE PER YEAR } \\
\hline PUBLIC HEALTH DEPARTMENTS (PHD) & $\mathbf{2 0 1 5}$ & $\mathbf{2 0 1 6}$ & $\mathbf{2 0 1 7}$ & $\mathbf{2 0 1 8}$ \\
\hline PHD9 & July & October & July & July \\
\hline PHD11 & June & August & June & July \\
\hline PHD12 & August & August & July & Jugust \\
\hline PHD13 & August & June & July & July \\
\hline PHD14 & August & August & July & July \\
\hline PHD15 & August & August & July & July \\
\hline PHD17 & July & July & September & July \\
\hline
\end{tabular}

\section{Discussion}

The presence of $S$. erythrocephalum in the studied areas, together with the proximity of urban centers along the indicated river channels, entails an incidence on humans. The incidence of bites has increased in recent years in the Valencian Autonomous Region, which has taken measures to reduce its repercussions $[10,11,14]$. This same effect is reflected in other areas of Spain, such as the Aragonese Autonomous Region [26]. In this work, the risk areas to which the municipalities are subjected are identified, establishing different ranges based on distances and population densities. In this regard, it is not possible to correlate these data with other data from Spain given the lack of knowledge of it.

In conclusion, and in clear harmony with other authors $[16,17,19]$, it is stated that $S$. erythrocephalum is one of the simuliid species with the greatest impact on the human population. Fortunately, its current vector potential in Spain is zero. As a result of all the above, it is necessary to acquire a global and integrative perspective to understand the phenological, ethological, and bioecological dynamics of this species. This knowledge facilitates implementation of both the necessary surveillance strategies and the most effective and appropriate control actions in each case as quickly as possible. In addition, the growing and numerous citizen complaints, as well as the innumerable medical treatments shown in this article and other regions of the national territory [26], should encourage health professionals to develop a greater knowledge of the characteristics of the pathologies due to this dipteran. This awareness correctly prepares health practitioners to face this type of clinical picture when manifested in citizens and helps predict expected areas of higher incidence resulting from living near the aforementioned hematophagus. Increased knowledge allows for discerning between types of bites of various arthropodsmore specifically, insects-identifying whether they are due to mosquitoes, simuliids, or others. In this way, the data collected in the health consultations of citizens due to these hematophagous and anthropophilic organisms would be of higher quality and reliability, thus being able to infer and analyze these data with greater scientific rigor. Finally, it is necessary to inform and educate the population of how this dipteran can impact their daily life.

Finally, simuliid species with obligate hematophagy of biomedical and veterinary importance [27] such as $S$. erythrocephalum are generalist species regarding the type of habitat in which they develop, Therefore, these species are capable of tolerating a wide range of ecological conditions. Under this premise and given the current climate change scenario in which certain authors and institutions predict a decrease in coldwater river habitats and greater environmental variability [28], it would be expected that the resulting conditions would favor the distribution and colonization of $S$. erythrocephalum to new geographic areas, increasing its harm to the well-being of citizens. Therefore, it is recommended to deepen the study of the ecological requirements of the breeding places of black fly species that, like $S$. erythrocephalum, can be considered a plague negatively affecting public health as a consequence of increased temperatures from climate change [29]. In this way, the knowledge of the bioecology of the species will play a crucial role when it comes to implementing treatment plans for preimaginal states, minimizing the sizes of their populations and reducing their incidences in public health. In the case of S. erythrocephalum, it is important to know that it is a species whose preimaginal development optimum is $20^{\circ} \mathrm{C}$, tolerates values higher than $25^{\circ} \mathrm{C}$, shows a narrow range of altitudinal tolerance 
with its optimum around 75 meters above sea level (masl), so that its distribution in the Valencian Autonomous Region is restricted to elevations between 5 and 240 masl [27]. Likewise, some authors ecologically described this species as preferring lentic and warm waters typical of the middle and lower sections of rivers [30].

In addition, the results provided offer useful information on the location of S. erythrocephalum, which will help in the development and execution of surveillance and control programs.

\section{Conclusions}

Simulium erythrocephalum is one of the main black fly species that threatens public health in Spain. In recent years, there have been frequent events of massive hatchings of this simuliid, whose nutritional habits have serious repercussions on health care systems. For this reason, it has been pertinent to carry out the present study. This work provides relevant information on the distribution of the species, risk areas, population density, and incidence of bites per municipality according to the flight range of adult specimens, which is useful. The results obtained can be implemented by researchers, public health practitioners, and policy makers as well as companies specializing in the control of noxious species to minimize the magnitude of the problem of black fly bites in the Spanish health system.

\section{Acknowledgments}

The authors especially wish to thank the Conselleria de Sanitat Universal i Salut Pública of the Generalitat Valenciana for their financial support and significant collaboration. María Barberá Riera is thanked for providing the data regarding bites.

\section{Conflicts of Interest}

Declarations of interest: none.

\section{Authorship Contributions}

David López-Peña, Álvaro Lis-Cantín, and Ricardo JiménezPeydró contributed equally to the data collection. David LópezPeña and Ricardo Jiménez-Peydró contributed significantly to the conception and design of the work. David López-Peña and Álvaro Lis-Cantín performed the analysis and interpretation of the data. David López-Peña wrote the first version of the manuscript. All three authors were responsible for the critical review of the article and approval of the final version for publication.

\section{Ethical Considerations}

No data from human subjects were used in the present work.

\section{Funding}

This work has been funded by the Conselleria de Sanitat Universal i Salut Pública of the Generalitat Valenciana, which has expressed its agreement to send the results obtained in the form of scientific articles for publication and public knowledge.

\section{References}

1. Cupp EW, Cupp MS (1997) Black fly (Diptera: Simuliidae) salivary secretions: importance in vector competence and disease. J Med Entomol 34: 87-94.

2. Ribeiro JMC, Francischetti IBM (2003) Role of arthropod saliva in blood feeding: Sialome and post-Sialome Perspectives. Annu Rev Entomol 48: 73-88.

3. Ruiz-Arrondo I, Alarcón-Elbal PM, Figueras L, DeLaCour-Estrella S, Muñoz A, et al. (2014) Expansión de los simúlidos (Diptera: Simuliidae) en España: Un nuevo reto para la salud pública y la sanidad animal. Boletín de la S.E.A 54: 193-200.

4. Adler PH, Currie DC, Wood DM (2004) The black flies (simuliidae) of North America. Cornell University Press, pp. 941.

5. Tucker ES (1918) Occurrences of black flies in Lousiana during recent years. Trans Kans Acad Sci 29: 65-75.

6. Rühm W (1983) Black-flies (Simuliidae, Diptera), a cause of annoyance and injury to livestock. Vet Med Rev (German Federal Republic) 1: 38-40.

7. Crosskey RW (1993) Blackflies (Simuliidae). In: Lane RP, Crosskey RW (Editors.), Medical insects and arachnids. Chapman and Hall, British Museum (Natural History), London, pp. 241-287.

8. Noirtin C, Boiteux P (1979) Mort de 25 animaux de ferme (dont 24 bovins) par piqures de simulies dans les Vosges. Bull Soc Vét Prat Fr 63: 41-54.

9. Ruiz-Arrondo I (2018) Estudio de Simulium erythrocephalum (De Geer, 1776) en Zaragoza: ecología e impacto en salud pública [Tesis Doctoral]. Zaragoza (España): Universidad de Zaragoza.

10. López-Peña D, Jiménez-Peydró R (2015) La invasión de la mosca negra en la Comunitat Valenciana. Direcció General de Salut Pública, Conselleria de Sanitat Universal i Salut Pública, Generalitat Valenciana. Viure en Salut 105(IV-Mosquit tigre i salut) p. 17-18.

11. Barbera Riera M, Bermell Melià R, González Morán F, Jiménez Perez J, Jiménez-Peydró R, et al. (2018) Manual de buenas prácticas frente a mosquito tigre y mosca negra para municipios de la Comunitat Valenciana. Generalitat Valenciana, Valencia, pp. 49.

12. Ruiz-Arrondo I, Martínez E, Kotter H, Figueras L, Muñoz A, et al. (2012) Blackfly outbreak in Zaragoza in 2011. Spread of blackflies in the Middle Ebro Valley in northeast Spain, p 22. In: Kúdela, M, Stloukalová V, (Eds.), Book of abstracts of the $5^{\text {th }}$ International Simuliid Symposium including the $32^{\text {nd }}$ meeting of the British Simuliid Group. 2012 Sep 3-7. Bratislava (Slovakia), Faculty of Natural Sciences, p: 40.

13. Ricoy-Llavero E (2015) Estudio de la dinámica poblacional de la comunidad de simúlidos en la Sierra de Segura [Trabajo Fin de Grado en Biología]. Jaén (España): Facultad de Ciencias Experimentales, Universidad de Jaén.

14. López-Peña D, Jiménez-Peydró R (2017) Contribución al conocimiento de las moscas negras (Diptera, Simuliidae) en la cuenca hidrográfica del Júcar. Boln Asoc Esp Ent 4: 167-196.

15. López-Peña D (2018) Simúlidos (Diptera: Simuliidae) de los ríos de la Comunidad Valenciana: Implicaciones en la salud pública y su control [Tesis Doctoral]. Paterna (España): Universitat de València.

16. Živković V (1971) Blackflies (Diptera, Simuliidae) of the Danube in Yugoslavia. Acta Vet 21: 225-236.

17. Ignjatović-Ćupina A, Zgomba M, Vujanović L, Konjević A, Marinković D, et al. (2006) An outbreak of Simulium erythrocephalum (De Geer, 1776) 
in the region of Novi Sad (Serbia) in 2006. Acta Entomol. Serbica 11 (Suppl): 97-114.

18. Post RJ (1983) The annual cycle of Simulium erythrocephalum (Diptera: Simuliidae) at a site in Norfolk. Freshw Biol 13: 379-388.

19. Ruiz-Arrondo I, Garza-Hernández JA, Reyes-Villanueva F, LucientesCurdi J, Rodríguez-Pérez M (2017) Human-landing rate, gonotrophic cycle length, survivorship, and public health importance of Simulium erythrocephalum in Zaragoza, northeastern Spain. Parasites \& Vectors 10: 175.

20. Garza-Hernández JF, De la Mora-Covarrubias A, Ruiz-Arrondo I (2018) Mating behaviour of Simulium erythrocephalum (De Geer, 1776) (Diptera: Simuliidae) in Zaragoza (Spain). An Biol 40: 129-133.

21. Živković V (1970) Les simulies (Diptera, Simuliidae) qui attaquent l'homme et les animaux domestiques. Acta Vet 20: 209-219.

22. Ham PJ, Bianco A (1983) Development of Onchocerca volvulus from cryopreserved microfilariae in three temperate species of laboratoryreared blackflies. Tropenmed. Parasitol 34: 137-139.

23. González G (1997) Claves para la identificación de las larvas y pupas de los simúlidos (Diptera) de la Península Ibérica. In: Claves de identificación de la flora y fauna de las aguas continentales de la Península Ibérica. Asociación Española de Limnología, Museo Nacional de Ciencias Naturales, Madrid, Publicación 6, pp: 77.

24. Jedlička, Kúdela M, Stloukalová V (2004) Key to the identification of blackfly pupae (Diptera: Simuliidae) of Central Europe. Biologia Bratislava 59 (Suppl 15): 157-178.

ISSN: 2574-1241

DOI: 10.26717/BJSTR.2021.39.006376

David López-Peña. Biomed J Sci \& Tech Res

(C) (†) This work is licensed under Creative

Submission Link: https://biomedres.us/submit-manuscript.php
25. López-Peña D, Jiménez-Peydró R (2018) Contribución al conocimiento de la simulidofauna (Diptera, Simuliidae) en la cuenca hidrográfica del río Mijares. Boln Asoc Esp Ent 42: 193-215.

26. (2013) Informe sobre las consultas atendidas por picaduras de insectos en atención primaria (2013). Zaragoza: Gobierno de Aragón, Servicio de Drogodependencia y Vigilancia de la Salud, Dirección General de Salud Pública.

27. López-Peña D, García-Roger EM, Jiménez-Peydró R (2020) Pre-imaginal black fly assemblages in streams of Eastern Spain: environmental and substrate requirements. Hydrobiologia 847: 1521-1538.

28. (2019) Intergovernmental Panel on Climate Change (IPCC). Climate change and land. IPCC Special Report on Climate Change, Desertification, Land Degradation, Sustainable Land Management, Food Security, and Greenhouse gas fluxes in Terrestrial Ecosystems. Summary for policymakers. World Meteorological Organization (WMO) and United Nations Environment Programme (UNEP), pp. 43.

29. Crosskey RW, Crosskey ME (2000) An investigation of the blackly fauna of Andalusia, southern Spain (Diptera: Simuliidae). J Nat Hist 34: 895951.

30. Martínez RE, Portillo M (1999) Faunistic and ecological study of Simuliids (Black-flies) (Diptera: Simuliidae) in a zone in southeast Spain. Mem Entomol Int 14: 605-623.

$\begin{array}{ll}\text { BIOMEDICAL } & \text { Assets of Publishing with us } \\ \text { RESEARCHES } & \text { - Global archiving of articles } \\ & \text { - Immediate, unrestricted online access } \\ & \text { - Rigorous Peer Review Process } \\ & \end{array}$

